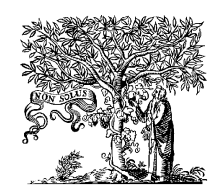

ELSEVIER

\title{
Electronic structure of vanadyl pyrophosphate: cluster model studies
}

\author{
M. Witko ${ }^{\mathrm{a}, *}$, R. Tokarz ${ }^{\mathrm{a}}$, J. Haber ${ }^{\mathrm{a}}$, K. Hermann ${ }^{\mathrm{b}}$ \\ a Institute of Catalysis and Surface Chemistry, Polish Academy of Sciences, ul. Niezapominajek, 30239 Cracow, Poland \\ ${ }^{\mathrm{b}}$ Fritz-Haber-Institute der Max-Planck-Gesellschaft, Faradayweg, 4-6, D-14195 Berlin, Germany
}

\begin{abstract}
The electronic properties of $(\mathrm{VO})_{2} \mathrm{P}_{2} \mathrm{O}_{7}\left(\begin{array}{lll}1 & 0 & 0\end{array}\right)$ surface are discussed using the cluster model and DFT method. The calculations indicate that present cluster models are size converged and the cluster as large as $\mathrm{V}_{10} \mathrm{P}_{6} \mathrm{O}_{50} \mathrm{H}_{30}$ can be considered the realistic model of the extended $(\mathrm{VO})_{2} \mathrm{P}_{2} \mathrm{O}_{7}\left(\begin{array}{lll}1 & 0 & 0\end{array}\right)$ surface. Vanadyl pyrophosphate forms a material of a mixed ionic-covalent character. Major covalent contributions participate in the $\mathrm{V}-\mathrm{O}$ as well as in the $\mathrm{P}-\mathrm{O}$ binding. The calculations reveal clear electronic differences between structurally different surface oxygen atoms. Triply coordinated oxygen sites (O3) are found to be the most negatively charged. Doubly coordinated oxygen sites $(\mathrm{O} 2)$ and oxygen atoms singly coordinated to phosphorous are characterize by a similar local reactivity with respect to electrophilic attacks. The strong nucleophilicity of surface oxygen sites together with the V3d character of HOMO/LUMO suggest that the interaction of adsorbate with the $(\mathrm{VO})_{2} \mathrm{P}_{2} \mathrm{O}_{7}(100)$ surface will lead to the activation of organic species proceeding via to $\mathrm{C}-\mathrm{H}$ bond splitting. () 2001 Elsevier Science B.V. All rights reserved.
\end{abstract}

Keywords: Vanadyl pyrophosphate; DFT method; Electronic structure

\section{Introduction}

Vanadium containing systems are widely used as components of various catalysts for many industrial processes that yield valuable products [1,2]. Among them vanadium-phosphorus oxides are one of the most remarkable both from scientific and practical point of views due to their great importance in technology. It is worth mentioning that $\mathrm{V}-\mathrm{O}-\mathrm{P}$ oxides have a rich chemistry where two factors: vanadium oxidation state and phosphorus to vanadium ratio can be varied [3-11]. Even at a P/V ratio restricted to 1, one can list several well-characterized phases with

\footnotetext{
* Corresponding author. Tel.: +48-12-6395156; fax: +48-12-425-1923.

E-mail addresses: ncwitko@cyf-kr.edu.pl (M. Witko), hermann@fhi-berlin.mpg.de (K. Hermann).
}

vanadium being in different formal oxidation state: $5+\left(\right.$ phosphates $\gamma, \delta$ - $\left.\mathrm{VOPO}_{4}\right), 4+$ (pyrophosphate $(\mathrm{VO})_{2} \mathrm{P}_{2} \mathrm{O}_{7}$ ) and $3+$ (monophosphate $\mathrm{VPO}_{4}$ ) (see for example $[3,4])$. One of the most important phases with the ratio $\mathrm{V} / \mathrm{P}=1$ is vanadyl pyrophosphate, $(\mathrm{VO})_{2} \mathrm{P}_{2} \mathrm{O}_{7}$, which is the catalyst in oxidation of $n$-butane to maleic anhydride (MA) [12-26]. The other phase of a great importance is vanadyl phosphate, $\mathrm{VOPO}_{4}$, which is always present as domains at pyrophosphate surface in the active catalysts of butane oxidation [14]. One has to stress that the oxidation on $n$-butane to MA is one of the most demanding chemical processes in which formally counting 14 electrons have to be exchanged. In this reaction eight hydrogen atoms need to be abstracted (which leads to the formation of four water molecules) and three oxygen atoms have to be inserted into an organic species. As the last step $\mathrm{C} 4$ chain must be cycled. 
This process leads to the formation of at least seven oxygen vacancies at catalysts surface and even if they do not appear simultaneously, the lattice of the catalyst has to accommodate most of them without structural collapse. One has also to add that oxidation of butane to MA is the only process of the selective oxidation which has been commercialized.

The different V-O-P oxides differ in vanadium oxidation state $(5+, 4+$ and $3+)$, in the type of connections of $\mathrm{V}-\mathrm{O}$ building units (corner/edge), as well as in $\mathrm{V}$ to $\mathrm{P}$ ratio $[3,4]$. As a consequence, there are characterized by different types of surface oxygen sites. At the surfaces of those compounds there are oxygen atoms singly coordinated to $\mathrm{V}$ or to $\mathrm{P}(\mathrm{V}=\mathrm{O}$, $\mathrm{P}=\mathrm{O}$ ), doubly coordinated bridging oxygens $(\mathrm{V}-\mathrm{O}-\mathrm{V}$, $\mathrm{V}-\mathrm{O}-\mathrm{P}, \mathrm{P}-\mathrm{O}-\mathrm{P})$, as well as triply coordinated bridging oxygens (to two $\mathrm{V}$ and one $\mathrm{P}$ atoms). The $\mathrm{V}(5+)$ phases like vanadyl phosphates or $(\alpha, \beta) \mathrm{VOPO}_{4}$, are built with isolated distorted $\mathrm{VO}_{6}$ octahedra connected by $\mathrm{PO}_{4}$ tetrahedra. One single octahedron (with a short $\mathrm{V}=\mathrm{O}$ bond) is linked to the orthophosphate group in such a way that each equatorial oxygen of $\mathrm{VO}_{6}$ shares a corner of one $\mathrm{PO}_{4}$ whereas vanadyl chains run in the perpendicular directions (vanadyl groups in $\mathrm{cis}$ position). The $\mathrm{V}(4+)$ phase-vanadyl pyrophosphate, $(\mathrm{VO})_{2} \mathrm{P}_{2} \mathrm{O}_{7}$, presents a structure in which two $\mathrm{VO}_{6}$ octahedra are joined by the edges. Pairs of octahedra are connected by $\mathrm{PO}_{4}$ tetrahedra which gives a layer structure in the $\left(\begin{array}{lll}1 & 0 & 0\end{array}\right)$ plane. The $\mathrm{V}=\mathrm{O}$ bonds in the octahedra pairs are in trans position and the layers are connected together by pyrophosphate groups. The $\mathrm{V}(3+)$ phase-vanadium monophosphate, $\mathrm{VPO}_{4}$, has an orthorhombic structure, in which two $\mathrm{VO}_{6}$ octahedra are joined by the edges.

Vanadyl pyrophosphate attracts scientist due to several reasons. As it has already been mentioned it is the catalyst in oxidation of $n$-butane to MA (the most intriguing and demanding process among the heterogeneuosly catalyzed selective oxidation reactions) and it is present during the same reaction starting from $n$-butenes. Therefore, in the present paper we discuss the electronic structure of vanadyl pyrophosphate, in particular the electronic states of structurally non-equivalent surface oxygen sites. There are experimental evidences that the oxygen atoms shared by one tetrahedron and pair of octahedra are the ones, that are directly involved in the oxidation process. The oxygen atoms shared by tetrahedron and one of octahedra from the pair as well as oxygen atoms linked to vanadium through the $\mathrm{V}=\mathrm{O}$ short bonds seem to remain nearly unaffected. Results of calculations allow us to point out nucleophilic/electrophilic active sites at the surface and therefore to suggest a type of reaction proceeding at that surface.

Most of the previously performed calculations [27-30] have been carried out by semiempirical methods. Schiott et al. [27] has done an analysis of the electronic structure of $(\mathrm{VO})_{2} \mathrm{P}_{2} \mathrm{O}_{7}$ surface by modeling it with the different cluster of $\mathrm{V}_{2} \mathrm{O}_{8}$ and $\mathrm{V}_{2} \mathrm{O}_{8}\left\{\mathrm{P}(\mathrm{OH})_{3}\right\}_{6}$ types. The main attention has been focused on the most favorable geometries of the 1,3-butadiene adsorbed species. The calculations have been carried out using the Extended Hückel method. Mechanism of the selective oxidation of $n$-butane into maleic anhydride has been studied by Haber et al. [28] using small cluster model $\mathrm{V}_{2} \mathrm{O}_{8}\left\{\mathrm{P}(\mathrm{OH})_{3}\right\}_{6}$. INDO type calculations have been performed to study the approach of butane molecule to such an active site. Different model has been applied to discuss the role of mixed-valence state in vanadium phosphate catalyst [29]. To model the catalytic active site the tetrameric vanadium-oxygen cluster has been proposed. In addition, a possible path for the interaction of 2,5-dihydrofuran with a lattice oxygen leading to the formation of maleic anhydride has been considered. The calculations were carried out by atomic superposition and electron delocalization (ASED) version of the Extended Hückel method. The energy differences between various vanadyl pyrophosphate crystal structures have been estimated by performing periodic Hartree-Fock calculation [30]. Those calculations have indicated that the experimentally determined structures for emerald-green and red-brown crystals of vanadyl pyrophosphate are expected to be among the most stable for those materials.

\section{Computational methods}

\subsection{Crystallographic structure of $(\mathrm{VO})_{2} \mathrm{P}_{2} \mathrm{O}_{7}$}

Bulk vanadyl pyrophosphate, $(\mathrm{VO})_{2} \mathrm{P}_{2} \mathrm{O}_{7}$, forms an orthorhombic layer crystal with lattice parameters $a=$ $7.725 \AA, b=16.576 \AA$ and $c=9.573 \AA$ [31]. Its unit cell contains 104 atoms, 16 of them being V, 16 $\mathrm{P}$ and the rest-O atoms. A building unit consists of 


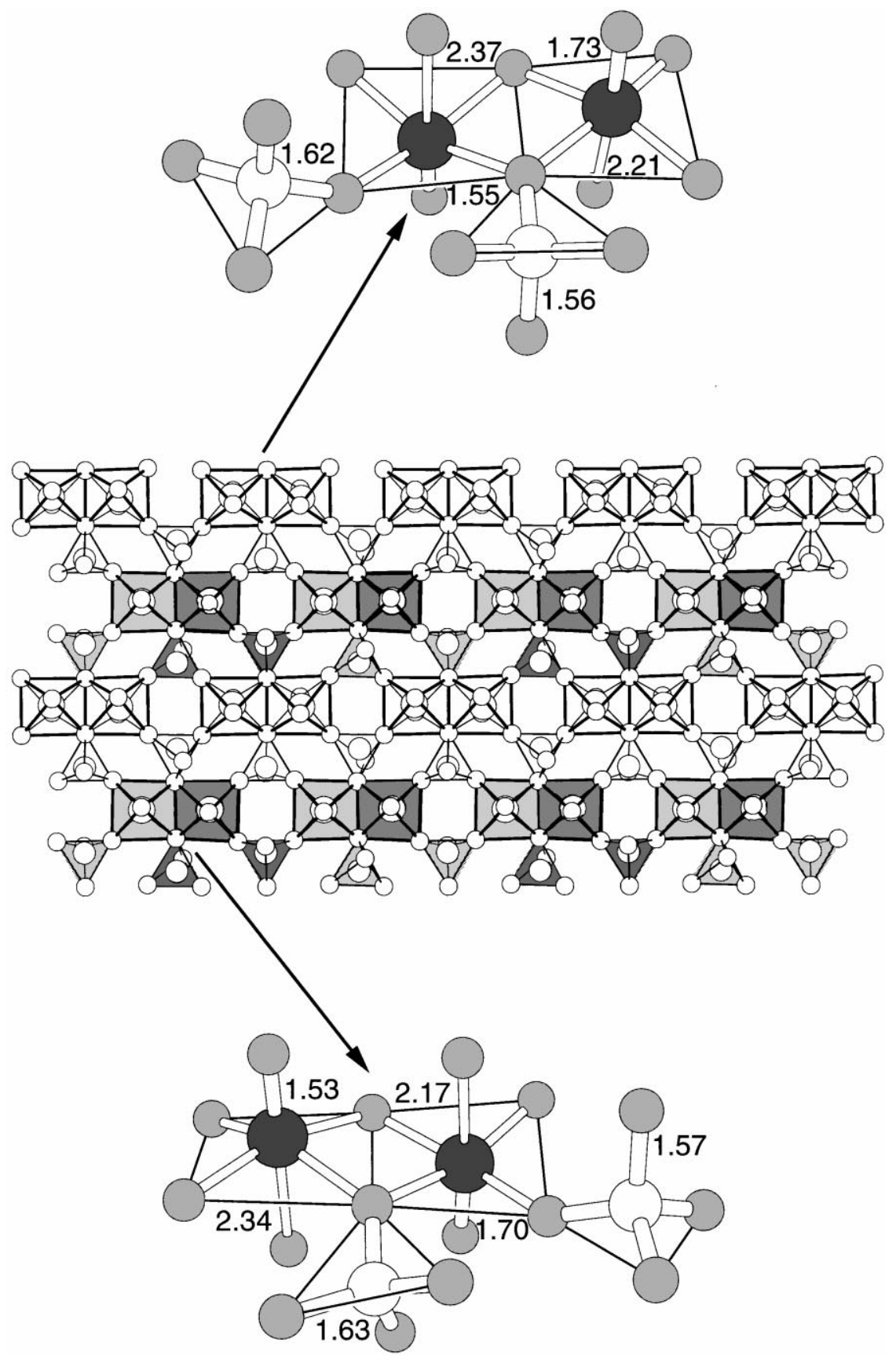

Fig. 1. Geometrical structure of the $(\mathrm{VO})_{2} \mathrm{P}_{2} \mathrm{O}_{7}\left(\begin{array}{lll}1 & 0 & 0\end{array}\right)$ surface. Two local sections at the surface are emphasized by magnification, note that every second row of $\mathrm{VO}_{6}$ octahedra and $\mathrm{PO}_{4}$ tetrahedra is structurally equivalent. In the building unit dark (light) gray balls refer to $\mathrm{V}(\mathrm{O})$ atoms while $\mathrm{P}$ centers are shown in white. All distances shown in the figure are given in $\AA$. 
(a)

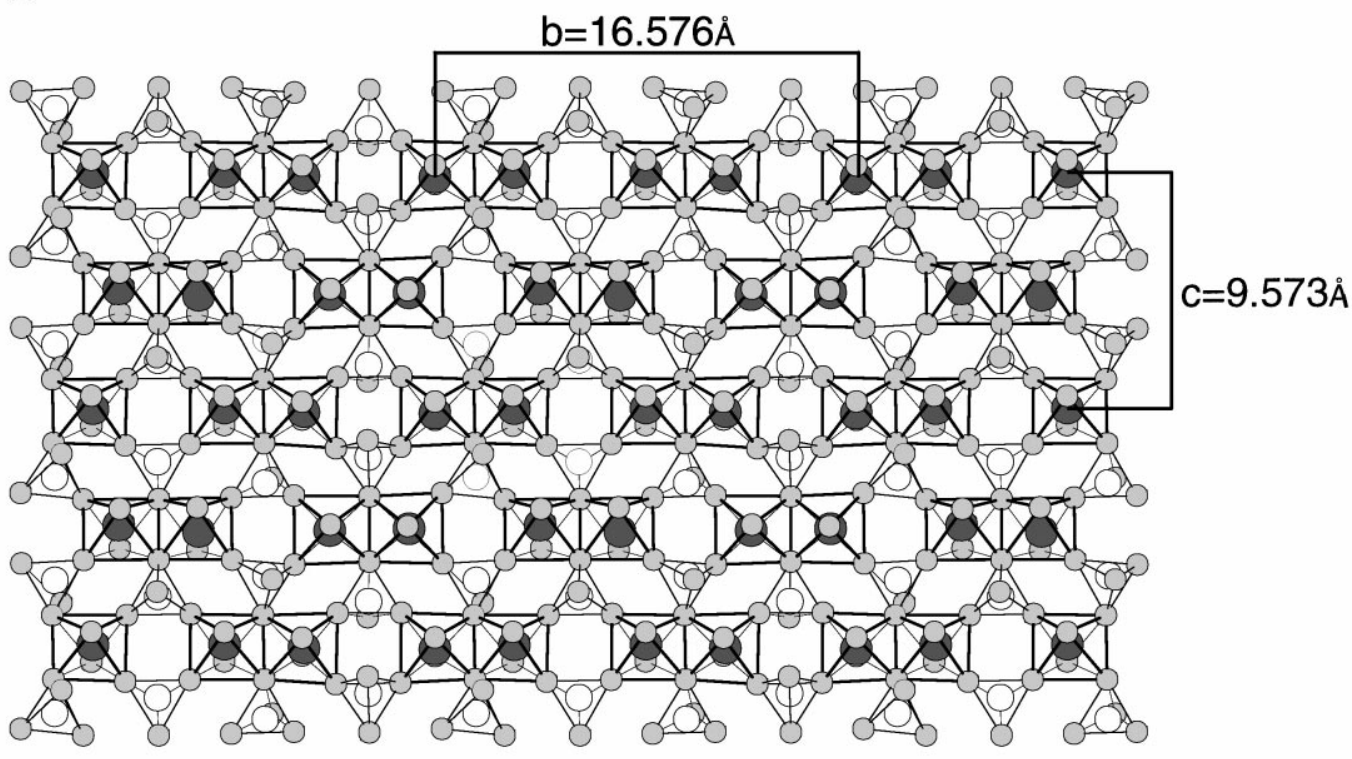

(b)

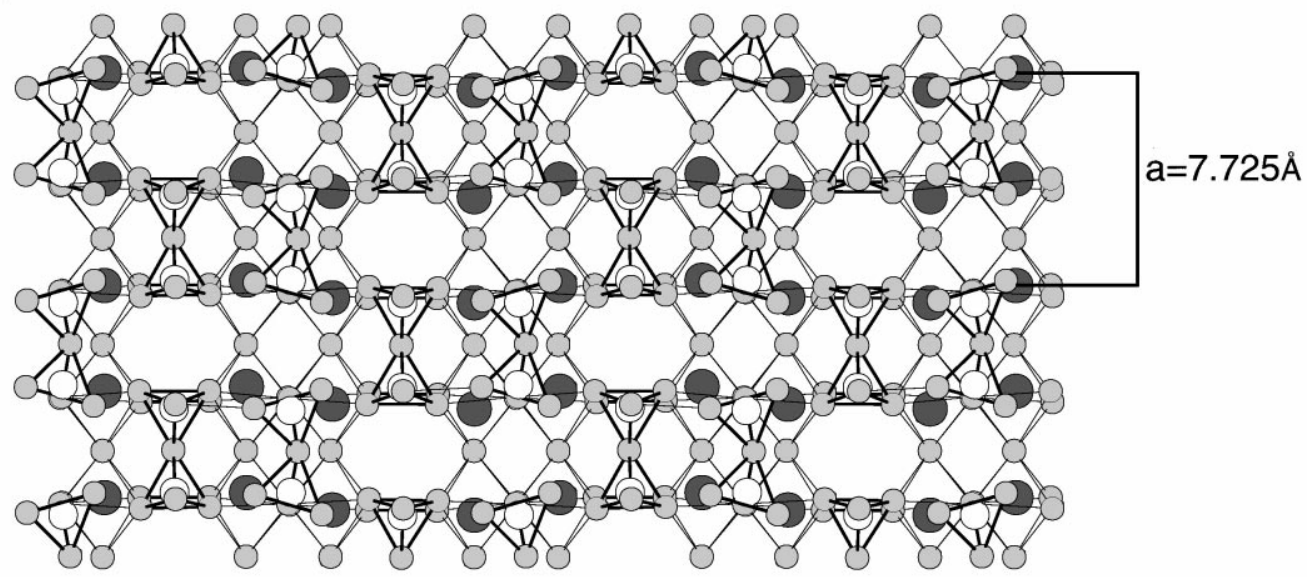

Fig. 2. Geometric structure of $(\mathrm{VO})_{2} \mathrm{P}_{2} \mathrm{O}_{7}$. Dark (light) gray balls refer to $\mathrm{V}(\mathrm{O})$ atoms while $\mathrm{P}$ centers are shown in white, (a) view along (1 $\left.\begin{array}{lll}0 & 0\end{array}\right)$ (b) view along (1 $\left.\begin{array}{lll}0 & 1\end{array}\right)$.

two pairs of V-O octahedra linked together via P-O tetrahedra (see Fig. 1). Due to a low symmetry of the crystal there exist four non-equivalent vanadium atoms (which form four long $\mathrm{V}-\mathrm{O}$ bonds ranging from 2.21 to $2.34 \AA$, and four short $\mathrm{V}-\mathrm{O}$ bonds varying from 1.53 to $1.73 \AA$ ), four non-equivalent phosphorous and 18 structurally different oxygen atoms. There are two values of $\mathrm{P}-\mathrm{O}-\mathrm{P}$ angle: 145 and $165^{\circ}$. The physical layers with normal direction along $(100)$ are composed of distorted $\mathrm{V}-\mathrm{O}$ octahedra and $\mathrm{P}-\mathrm{O}$ tetrahedra. Vanadium-oxygen octahedra are edge linked into pairs (two octahedra share two equatorial oxygen atoms and the coupling is orthogonal to $\mathrm{V}=\mathrm{O}$ bonds) (see Fig. 2a). Along $a$ direction each $\mathrm{VO}_{6}$ octahedron 
shares an opposite corner with the another octahedron, see Fig. 2b, forming chains along alternative short and long $\mathrm{V}-\mathrm{O}$ bonds. One oxygen atom from $\mathrm{PO}_{4}$ group is common with another tetrahedron $(\mathrm{P}-\mathrm{O}-\mathrm{P}$ bond $)$ forming pyrophosphate group, $\mathrm{P}_{2} \mathrm{O}_{7}$. The second oxygen atom is shared between one tetrahedron and two vanadium atoms of the coupled octahedra (triply coordinated oxygen, in $b c$ plane) whereas the remaining two oxygens are shared with $\mathrm{VO}_{6}$ octahedra belonging to different chains (in $b c$ plane). To summarize, one can say that the framework of $(\mathrm{VO})_{2} \mathrm{P}_{2} \mathrm{O}_{7}$ consists of sheets made with a pairs of edge-sharing $\mathrm{VO}_{6}$ with trans short $\mathrm{V}=\mathrm{O}$ bonds. A pair of $\mathrm{VO}_{6}$ octahedra is equatorial linked to $\mathrm{PO}_{4}$ tetrahedra. These sheets are stacked upon each other so as to form a double column of a distorted $\mathrm{VO}_{6}$ (chain of $\mathrm{V}=\mathrm{O}-\mathrm{V}=\mathrm{O}-\mathrm{V} \ldots$ bonds) which is parallel to bent pyrophosphate groups. In other words, the $b c$ type layers are joined together through $\mathrm{V}-\mathrm{O}=\mathrm{V}$ and $\mathrm{P}-\mathrm{O}-\mathrm{P}$ bonds resulting in chains of $\mathrm{VO}_{6}$ octahedra sharing opposite corners and $\mathrm{P}_{2} \mathrm{O}_{7}$ pyrophosphate groups. Another approach is to consider the lattice as containing two closed-packed layers of oxygen atoms which lie parallel to the $b c$-plane at approximately $1 / 4$ and $3 / 4$ along the $a$-axis. These layering planes are made up entirely of the basal oxygens of vanadium octahedra and pyrophosphate tetrahedra [5]. There are some experimental evidences indicating that the oxygen atoms shared by one tetrahedron and two octahedra (triply coordinated oxygen sites) are the ones, that are directly involved in the oxidation process. The oxygen atoms shared with octahedra from the different chains (doubly coordinated oxygen centers) as well as oxygen atoms linked to vanadium through the $\mathrm{V}=\mathrm{O}$ short bonds (singly coordinated oxygen sites) seem to remain nearly unaffected.

Nowadays, it is generally accepted that the crystal plane parallel to $(100)$ contains the active sites for $n$-butane oxidation. Experimental results of the determination of a maximum yield in maleic anhydride, as a function of the $\mathrm{P} / \mathrm{V}$ ratio, seem to indicate two possible truncations present at the surface of the most active and selective catalyst. First, it is the truncation in which the surface is terminated by the pendant groups of pyrophosphate that surround the pairs of $\mathrm{V}-\mathrm{O}$ pyramids. In this case vanadium ions are buried inside a cavity or cleft in the walls formed by $\mathrm{P}_{2} \mathrm{O}_{7}$ groups. In the second type of truncation of the crystallites the orthophosphate groups terminate the surface. Here, the vanadium atoms are more easily accessible for the reactant molecules from a gas phase. In our modeling we have focused our attention to the second type of truncation where the (100) surface is built of the pairs of $\mathrm{VO}_{5}$ square pyramids coupled by edges and surrounded by $\mathrm{PO}_{4}$ groups. Such a cleaved surface is characterized by a following set of the structurally different surface oxygen atoms: singly coordinated either to vanadium or phosphorous atoms, $(\mathrm{V}=\mathrm{O}, \mathrm{P}=\mathrm{O})$, (O1), doubly coordinated, (V-O-P), (O2), and triply coordinated (to two $\mathrm{V}$ and one $\mathrm{P}$ centers), (O3).

\subsection{Model and method}

All theoretical treatments of catalytic systems are based on models, by definition, simplified with respect to the real systems [32]. The quality of theoretical results and their relevance with respect to experimental data for the real system is determined by basically two approximations, i.e. those used to simplify the system geometry, and those used to evaluate the electronic structure for model system. Both approximations influence each other and there are no simple criteria to select system geometry or theoretical methods to yield a given accuracy.

To model the cleaved (VO) $)_{2} \mathrm{P}_{2} \mathrm{O}_{7}\left(\begin{array}{lll}1 & 0 & 0\end{array}\right)$ surface, a cluster model is used. The substrate atoms are cut out of the surface of the catalyst, i.e. the assumption of a localized interaction near the adsorption site and the neglect of the long-range interactions is introduced. In all cases the formal oxidation states for all atoms and the neutrality of the cluster are assumed. To take into account the effect of structural and electronic coupling with the environment, hydrogen atoms saturate each cluster. The main drawback of the cluster model is the incorrect treatment of atoms at the cluster periphery, which manifests itself in the dependence of the calculated physical and chemical parameters on the size and geometry of the cluster. Therefore, clusters of different size and shape, exhibiting different local states, are examined. The following two sets of surface clusters are discussed: those, composed of two square pyramids, but differing in charge, $\mathrm{V}_{2} \mathrm{P}_{6} \mathrm{O}_{26}$, $\mathrm{V}_{2} \mathrm{P}_{6} \mathrm{O}_{26} \mathrm{H}_{16}{ }^{2+}, \mathrm{V}_{2} \mathrm{P}_{6} \mathrm{O}_{26} \mathrm{H}_{14}, \mathrm{~V}_{2} \mathrm{P}_{6} \mathrm{O}_{26} \mathrm{H}_{12}{ }^{2-}$ (see Fig. 3a) and those, which have different size but are neutral, $\mathrm{V}_{2} \mathrm{O}_{8} \mathrm{H}_{8}, \mathrm{~V}_{2} \mathrm{P}_{6} \mathrm{O}_{26} \mathrm{H}_{14}, \mathrm{~V}_{10} \mathrm{P}_{6} \mathrm{O}_{50} \mathrm{H}_{30}$, $\mathrm{V}_{14} \mathrm{P}_{10} \mathrm{O}_{70} \mathrm{H}_{34}, \mathrm{~V}_{18} \mathrm{P}_{16} \mathrm{O}_{96} \mathrm{H}_{40}$ (see Fig. 3b). The first set serves to study the saturation effect whereas the 
(a)

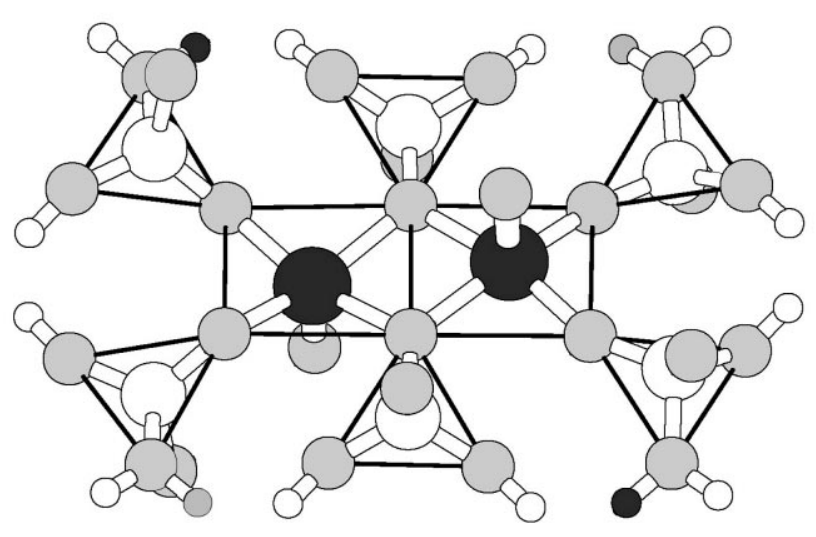

(b)

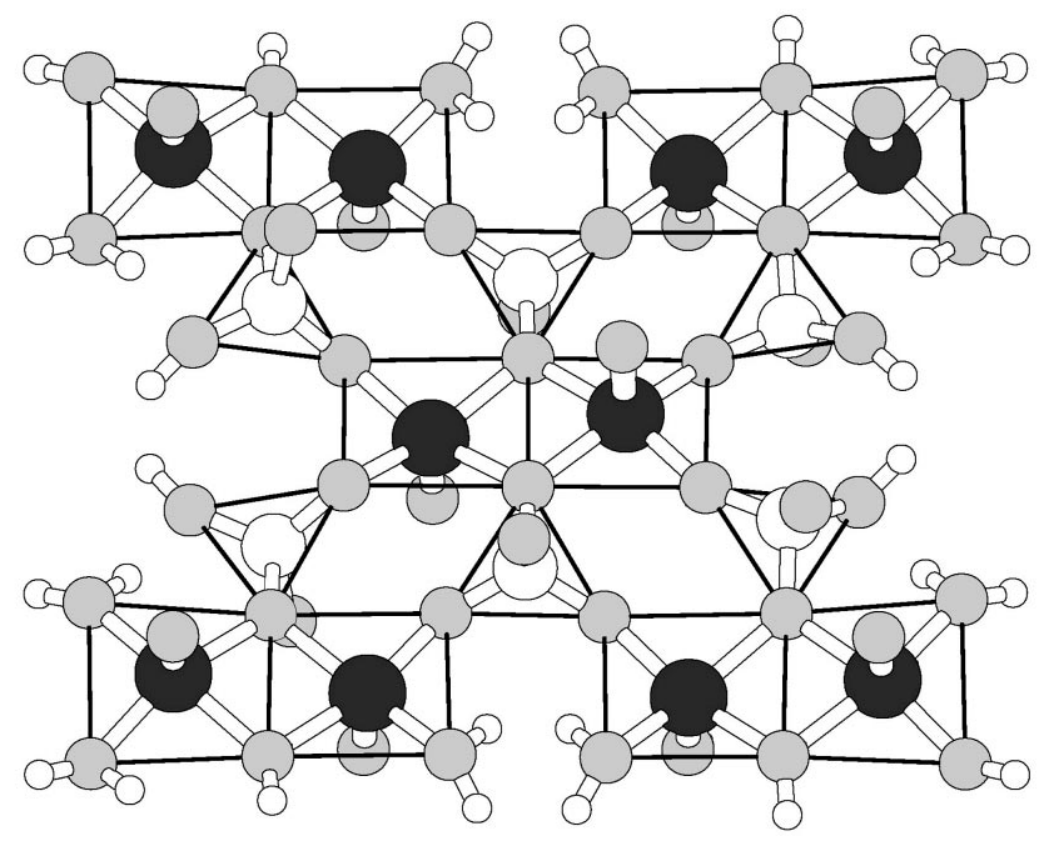

Fig. 3. Clusters used to model $(100)$ surface of $(\mathrm{VO})_{2} \mathrm{P}_{2} \mathrm{O}_{7}$. Dark (light) gray big balls refer to $\mathrm{V}(\mathrm{O})$ atoms while $\mathrm{P}$ centers are shown in white, (a) $\mathrm{V}_{2} \mathrm{P}_{6} \mathrm{O}_{26} \mathrm{H}_{16}{ }^{2+}$ cluster, small black balls refer to hydrogen atoms removed when forming $\mathrm{V}_{2} \mathrm{P}_{6} \mathrm{O}_{26} \mathrm{H}_{14}$ whereas hydrogen removed to form $\mathrm{V}_{2} \mathrm{P}_{6} \mathrm{O}_{26} \mathrm{H}_{12}{ }^{2-}$ cluster are denoted as gray and black small balls. (b) $\mathrm{V}_{10} \mathrm{P}_{6} \mathrm{O}_{50} \mathrm{H}_{30}$ cluster.

other one to achieve cluster size convergence. Clusters are chosen in such a way that each smaller cluster forms a subsection of the bigger one.

The electronic structure of the vanadyl pyrophosphate $(100)$ surface is evaluated using two ap- proaches, the semiempirical ZINDO (for obtaining qualitative trends in large model systems) [33-35], and ab initio Density Functional Theory (DFT) [36,37] (for a quantitative account of small model systems) methods. The use of different methods to 
determine electronic structures results in a complete electronic description of the catalytic model system, and excludes the dependence of the calculated properties on the method. The INDO type treatment is applied to clusters as large as $\mathrm{V}_{18} \mathrm{P}_{16} \mathrm{O}_{96} \mathrm{H}_{40}$ to select a cluster whose electronic properties are converged with respect to the size of the cluster. The DFT calculations are performed for clusters up to $\mathrm{V}_{10} \mathrm{P}_{6} \mathrm{O}_{50} \mathrm{H}_{30}$ to discuss details of the electronic structure. In the calculations the Kohn-Sham orbitals are represented by linear combinations of atomic orbitals (LCAOs) using all-electron basis sets of contracted Gaussians, which are taken from DFT optimization for the atoms [38]. In the calculation the program package DeMon [39] is applied. The exchange and correlation is approximated by the local spin density approximation (LSDA) based on the Vosko-Wilk-Nusair functional [40].

The electronic properties of the clusters are elaborated by discussing the following electronic parameters: atomic charges, bond order indices, wavefunctions and distribution of populations of molecular orbitals (in particular the HOMO). Atomic charges follow from the Mulliken population analysis [41] and provide us with information about ionic (electrostatic) contributions to binding in the system. Bond order indices [42,43] describe covalent contribution to the interatomic bonds and may serve as a measure of their strength. Characteristics of orbitals of the HOMO/LUMO type, which are responsible for the interaction with approaching molecule, identifies atoms involved in these orbitals whereas plots of respective wavefunctions provide direct information about the type of atomic orbitals which are involved.

\section{Results and discussion}

Table 1 lists results of Mulliken population and Mayer bond indices for the selected atoms (shown in Fig. 4) of $\mathrm{V}_{2} \mathrm{P}_{6} \mathrm{O}_{26}, \mathrm{~V}_{2} \mathrm{P}_{6} \mathrm{O}_{26} \mathrm{H}_{16}{ }^{2+}, \mathrm{V}_{2} \mathrm{P}_{6} \mathrm{O}_{26} \mathrm{H}_{14}$ and $\mathrm{V}_{2} \mathrm{P}_{6} \mathrm{O}_{26} \mathrm{H}_{12}{ }^{2-}$ clusters (see Fig. 3a). This set of clusters represents different types of saturation. In case of the first cluster, $\mathrm{V}_{2} \mathrm{P}_{6} \mathrm{O}_{26}$ no peripheral saturation is applied and no formal oxidation states for atoms constituting the cluster are assumed. The $\mathrm{V}_{2} \mathrm{P}_{6} \mathrm{O}_{26} \mathrm{H}_{16}{ }^{2+}$ cluster is selected by saturating oxygen atom from the $\mathrm{P}-\mathrm{O}$ groups according to its missing bonds, i.e. four $\mathrm{H}_{2} \mathrm{O}$ and eight $\mathrm{OH}$ species are formed. The choice of the $\mathrm{V}_{2} \mathrm{P}_{6} \mathrm{O}_{26} \mathrm{H}_{14}$ cluster follows from the requirement of the cluster neutrality. In $\mathrm{V}_{2} \mathrm{P}_{6} \mathrm{O}_{26} \mathrm{H}_{12}{ }^{2-}$ cluster each oxygen atoms from $\mathrm{P}-\mathrm{O}$ groups is saturated

Table 1

Mulliken population and Mayer bond indices for the selected atoms (see Fig. 4) of $\mathrm{V}_{2} \mathrm{P}_{6} \mathrm{O}_{26}, \mathrm{~V}_{2} \mathrm{P}_{6} \mathrm{O}_{26} \mathrm{H}_{16}{ }^{2+}, \mathrm{V}_{2} \mathrm{P}_{6} \mathrm{O}_{26} \mathrm{H}_{14}$ and $\mathrm{V}_{2} \mathrm{P}_{6} \mathrm{O}_{26} \mathrm{H}_{12}{ }^{2-}$ clusters obtained by DFT treatment

\begin{tabular}{|c|c|c|c|c|}
\hline Atoms & $\mathrm{V}_{2} \mathrm{P}_{6} \mathrm{O}_{26}$ & $\mathrm{~V}_{2} \mathrm{P}_{6} \mathrm{O}_{26} \mathrm{H}_{16}{ }^{2+}$ & $\mathrm{V}_{2} \mathrm{P}_{6} \mathrm{O}_{26} \mathrm{H}_{14}$ & $\mathrm{~V}_{2} \mathrm{P}_{6} \mathrm{O}_{26} \mathrm{H}_{12}{ }^{2-}$ \\
\hline \multicolumn{5}{|l|}{ Charges } \\
\hline $\mathrm{V} 1=\mathrm{O} 1$ & $1.00 /-0.15$ & $1.00 /-0.21$ & $0.99 /-0.23$ & $0.95 /-0.26$ \\
\hline $\mathrm{V} 2=\mathrm{O} 1^{\prime}$ & $1.15 /-0.18$ & $1.13 /-0.27$ & $1.11 /-0.30$ & $1.09 /-0.33$ \\
\hline $\mathrm{P} 1=\mathrm{O} 1$ & $1.19 /-0.26$ & $1.18 /-0.60$ & $1.18 /-0.64$ & $1.14 /-0.68$ \\
\hline $\mathrm{P} 2=\mathrm{O} 1^{\prime}$ & $1.21 /-0.32$ & $1.20 /-0.57$ & $1.19 /-0.60$ & $1.15 /-0.65$ \\
\hline $\mathrm{V} 1-\mathrm{O} 2-\mathrm{P} 1$ & -0.51 & -0.58 & -0.58 & -0.59 \\
\hline $\mathrm{V} 1-\mathrm{O} 3-\mathrm{V} 2-\mathrm{P} 2$ & -0.71 & -0.70 & -0.71 & -0.71 \\
\hline \multicolumn{5}{|c|}{ Distances $(R)$ and bond orders } \\
\hline$R(\mathrm{~V} 1=\mathrm{O} 1)=1.55$ & 2.37 & 2.39 & 2.36 & 2.34 \\
\hline$R\left(\mathrm{~V} 2=\mathrm{O}^{\prime}{ }^{\prime}\right)=1.73$ & 2.30 & 2.31 & 2.27 & 2.31 \\
\hline$R(\mathrm{P} 1=\mathrm{O} 1)=1.63$ & 1.10 & 1.67 & 1.66 & 1.67 \\
\hline$R\left(\mathrm{P} 2=\mathrm{O}^{\prime}\right)=1.56$ & 1.32 & 1.85 & 1.81 & 1.85 \\
\hline$R(\mathrm{~V} 1-\mathrm{O} 2)=2.00$ & 0.83 & 0.51 & 0.49 & 0.51 \\
\hline$R(\mathrm{P} 1-\mathrm{O} 2)=1.53$ & 1.13 & 1.33 & 1.36 & 1.33 \\
\hline$R(\mathrm{~V} 1-\mathrm{O} 3)=2.09$ & 0.42 & 0.38 & 0.38 & 0.38 \\
\hline$R(\mathrm{~V} 2-\mathrm{O} 3)=2.05$ & 0.42 & 0.36 & 0.36 & 0.36 \\
\hline$R(\mathrm{P} 2-\mathrm{O} 3)=1.56$ & 0.90 & 1.03 & 1.08 & 1.03 \\
\hline
\end{tabular}




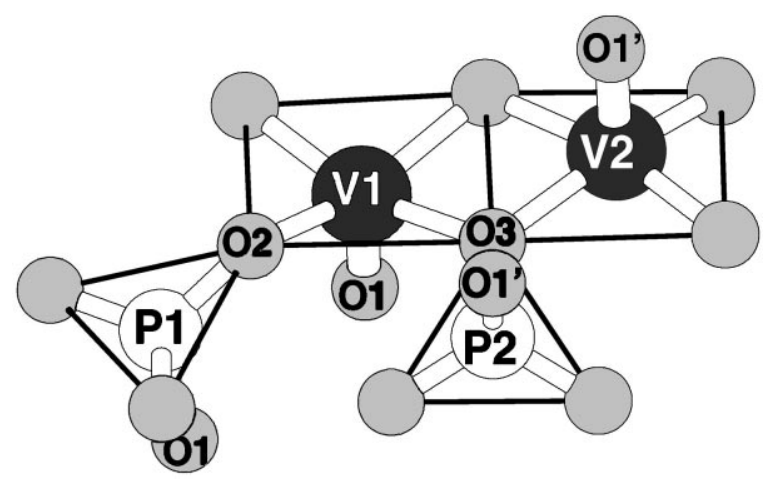

Fig. 4. Fragment $\mathrm{V}_{2} \mathrm{P}_{2} \mathrm{O}_{14}$ (with atom notation) used to describe a central part of all clusters.

by one hydrogen forming $\mathrm{OH}$ group. In the remaining three clusters $\left(\mathrm{V}_{2} \mathrm{P}_{6} \mathrm{O}_{26} \mathrm{H}_{16}{ }^{2+}, \mathrm{V}_{2} \mathrm{P}_{6} \mathrm{O}_{26} \mathrm{H}_{14}\right.$, $\left.\mathrm{V}_{2} \mathrm{P}_{6} \mathrm{O}_{26} \mathrm{H}_{12}{ }^{2-}\right) 4+, 5+, 2-$ and $1+$ formal oxidation states are assumed for vanadium, phosphorous, oxygen and hydrogen atoms, respectively. Similar studies were performed for different clusters modeling $\mathrm{V}_{2} \mathrm{O}_{5}\left(\begin{array}{lll}0 & 1 & 0\end{array}\right)$ surface, where no saturation or saturation resulting in the formation of surface either $\mathrm{OH}$ or $\mathrm{H}_{2} \mathrm{O}$ species was discussed [44]. From Table 1 one sees only slight variation in electronic parameters for clusters with different saturation. The positive charges characterizing vanadium atoms vary between 0.95 and 1.00 for $\mathrm{V} 1$ and 1.09 and 1.13 for V2. The singly coordinated oxygen $\mathrm{O} 1$ bonded to more positive metal ion possesses smaller negative charge (0.21-0.26) in comparison to the oxygen $\mathrm{O}^{\prime}$ singly coordinated to more oxidized vanadium $\mathrm{V} 2$. The differences in charges become negligible if we compare the relative charges of differently coordinated oxygen. In all cases the charge differences between oxygen singly coordinated to vanadium (O1) and oxygen doubly coordinated $\mathrm{V}-\mathrm{O}-\mathrm{P}(\mathrm{O} 2)$ and between that oxygen and oxygen triply coordinated (O3) are about 0.3 and $0.1 \mathrm{e}$. In fact the same applies to $\mathrm{V}_{2} \mathrm{P}_{6} \mathrm{O}_{26}$ cluster with no peripheral saturation. The only larger difference concerns its doubly coordinated oxygen, which is less negatively charged and more strongly/weakly bonded to $\mathrm{V} / \mathrm{P}$ atoms. The saturation effect is clearly seen from the HOMO description. Fig. 5 shows the population distribution for the orbitals of HOMO type for $\mathrm{V}_{2} \mathrm{P}_{6} \mathrm{O}_{26}$ and $\mathrm{V}_{2} \mathrm{P}_{6} \mathrm{O}_{26} \mathrm{H}_{16}{ }^{2+}$ clusters (for the remaining $\mathrm{V}_{2} \mathrm{P}_{6} \mathrm{O}_{26} \mathrm{H}_{14}, \mathrm{~V}_{2} \mathrm{P}_{6} \mathrm{O}_{26} \mathrm{H}_{12}{ }^{2-}$ clusters the pictures are similar to that for $\mathrm{V}_{2} \mathrm{P}_{6} \mathrm{O}_{26} \mathrm{H}_{16}{ }^{2+}$ ). The population distribution for HOMO of the first cluster is characterized by the contribution of atomic orbitals of peripheral oxygen atoms. For the remaining clusters the main contribution comes from vanadium atoms so it is in the case of large $\mathrm{V}_{10} \mathrm{P}_{6} \mathrm{O}_{50} \mathrm{H}_{30}$ cluster, which will be discussed below. This indicates that $\mathrm{V}_{2} \mathrm{P}_{6} \mathrm{O}_{26}$ cluster, in contrast to saturated small clusters, can not be used to describe the electronic structure of vanadyl pyrophosphate.

Table 2 summarizes the electronic parameters obtained using the ZINDO approach for the $\mathrm{V}_{2} \mathrm{P}_{2} \mathrm{O}_{6}$

(a)

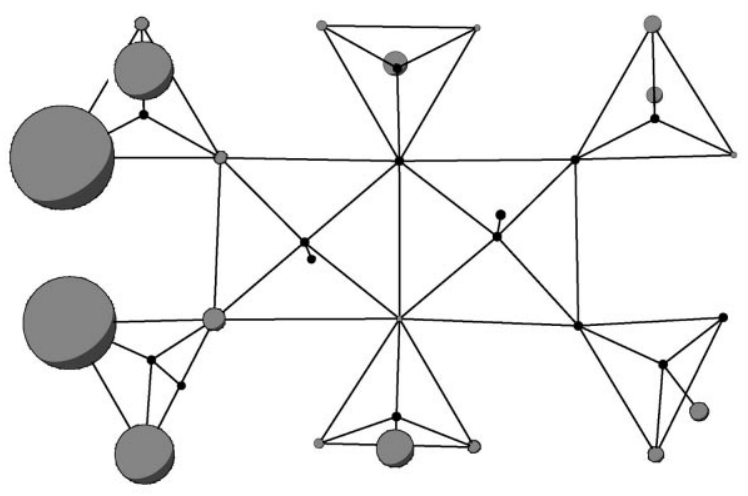

(b)

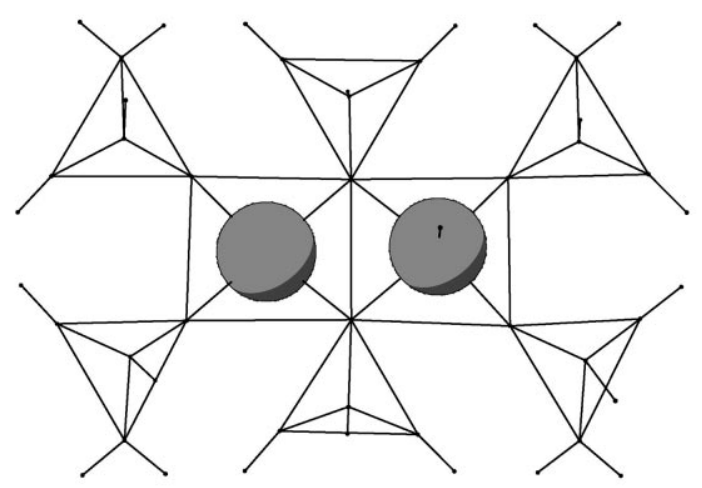

Fig. 5. Population distribution for the orbitals of HOMO type (a) $\mathrm{V}_{2} \mathrm{P}_{6} \mathrm{O}_{26}$ cluster (b) $\mathrm{V}_{2} \mathrm{P}_{6} \mathrm{O}_{26} \mathrm{H}_{16}{ }^{2+}$ cluster, note that HOMO character is the same for $\mathrm{V}_{2} \mathrm{P}_{6} \mathrm{O}_{26} \mathrm{H}_{16}{ }^{2+}, \mathrm{V}_{2} \mathrm{P}_{6} \mathrm{O}_{26} \mathrm{H}_{14}, \mathrm{~V}_{2} \mathrm{P}_{6} \mathrm{O}_{26} \mathrm{H}_{12}{ }^{2-}$ clusters. The respective Mulliken populations determine atomic radii, cut has been done through (100) plane. 
Table 2

Electronic parameters obtained using ZINDO approach for the $\mathrm{V}_{2} \mathrm{P}_{2} \mathrm{O}_{6}$ fragment (see Fig. 4) in $\mathrm{V}_{2} \mathrm{O}_{8} \mathrm{H}_{8}, \mathrm{~V}_{2} \mathrm{P}_{6} \mathrm{O}_{26} \mathrm{H}_{14}, \mathrm{~V}_{10} \mathrm{P}_{6} \mathrm{O}_{50} \mathrm{H}_{30}$, $\mathrm{V}_{14} \mathrm{P}_{10} \mathrm{O}_{70} \mathrm{H}_{34}$, and $\mathrm{V}_{18} \mathrm{P}_{16} \mathrm{O}_{96} \mathrm{H}_{40}$ clusters

\begin{tabular}{|c|c|c|c|c|}
\hline Bonds & $\mathrm{V}_{2} \mathrm{O}_{8} \mathrm{H}_{6}$ & $\mathrm{~V}_{10} \mathrm{P}_{6} \mathrm{O}_{50} \mathrm{H}_{20}$ & $\mathrm{~V}_{14} \mathrm{P}_{10} \mathrm{O}_{70} \mathrm{H}_{20}$ & $\mathrm{~V}_{18} \mathrm{P}_{16} \mathrm{O}_{96} \mathrm{H}_{22}$ \\
\hline \multicolumn{5}{|l|}{ Charges } \\
\hline $\mathrm{V} 1=\mathrm{O} 1$ & $1.15 /-0.37$ & $1.20 /-0.32$ & $1.20 /-0.32$ & $1.20 /-0.31$ \\
\hline $\mathrm{V} 2=\mathrm{O} 1^{\prime}$ & $1.16 /-0.34$ & $1.16 /-0.31$ & $1.15 /-0.31$ & $1.16 /-0.30$ \\
\hline $\mathrm{P} 1=\mathrm{O} 1$ & - & $1.05 /-0.44$ & $0.97 /-0.43$ & $0.97 /-0.43$ \\
\hline $\mathrm{P} 2=\mathrm{O} 1^{\prime}$ & - & $1.06 /-0.47$ & $1.06 /-0.47$ & $1.06 /-0.47$ \\
\hline $\mathrm{V} 1-\mathrm{O} 2-\mathrm{P} 1$ & -0.50 & -0.49 & -0.48 & -0.48 \\
\hline $\mathrm{V} 1-\mathrm{O} 3-\mathrm{V} 2-\mathrm{P} 1$ & -0.47 & -0.48 & -0.48 & -0.48 \\
\hline \multicolumn{5}{|c|}{ Distances $(R)$ and bond orders } \\
\hline$R(\mathrm{~V}=\mathrm{O})=1.55$ & 2.60 & 2.64 & 2.65 & 2.65 \\
\hline$R(\mathrm{~V}=\mathrm{O})=1.73$ & 1.94 & 1.95 & 1.95 & 1.95 \\
\hline$R(\mathrm{P}=\mathrm{O})=1.63$ & - & 0.92 & 0.91 & 0.91 \\
\hline$R(\mathrm{P}=\mathrm{O})=1.56$ & - & 1.04 & 1.04 & 1.04 \\
\hline$R(\mathrm{~V}-\mathrm{O})=2.00$ & 1.13 & 0.98 & 0.98 & 0.98 \\
\hline$R(\mathrm{P}-\mathrm{O})=1.53$ & 0.94 & 0.93 & 0.93 & 0.93 \\
\hline$R(\mathrm{~V} 1-\mathrm{O})=2.09$ & 0.69 & 0.71 & 0.71 & 0.70 \\
\hline$R(\mathrm{~V} 2-\mathrm{O})=2.05$ & 0.69 & 0.72 & 0.71 & 0.71 \\
\hline$R(\mathrm{P}-\mathrm{O})=1.56$ & 0.93 & 0.78 & 0.79 & 0.79 \\
\hline
\end{tabular}

fragment (shown in Fig. 4) in $\mathrm{V}_{2} \mathrm{O}_{8} \mathrm{H}_{8}, \mathrm{~V}_{2} \mathrm{P}_{6} \mathrm{O}_{26} \mathrm{H}_{14}$, $\mathrm{V}_{10} \mathrm{P}_{6} \mathrm{O}_{50} \mathrm{H}_{30}, \quad \mathrm{~V}_{14} \mathrm{P}_{10} \mathrm{O}_{70} \mathrm{H}_{34}$ and $\mathrm{V}_{18} \mathrm{P}_{16} \mathrm{O}_{96} \mathrm{H}_{40}$ clusters. Here, for all atoms in clusters, the formal oxidation states are assumed. One can note that the calculated values are almost the same for all clusters belong $\mathrm{V}_{10} \mathrm{P}_{6} \mathrm{O}_{50} \mathrm{H}_{30}$, that indicates size convergence and shows that this cluster can be considered as a realistic representation of the extended $(\mathrm{VO})_{2} \mathrm{P}_{2} \mathrm{O}_{7}\left(\begin{array}{lll}1 & 0 & 0\end{array}\right)$ surface.

The detailed electronic structure of the $\left(\begin{array}{lll}1 & 0 & 0\end{array}\right)$ surface of vanadyl pyrophosphate is analyzed using the DFT method. The results (i.e. the atomic charges and bond orders) of those calculations done for $\mathrm{V}_{2} \mathrm{O}_{8} \mathrm{H}_{8}$, $\mathrm{V}_{2} \mathrm{P}_{6} \mathrm{O}_{26} \mathrm{H}_{14}, \quad \mathrm{~V}_{10} \mathrm{P}_{6} \mathrm{O}_{50} \mathrm{H}_{30}$ clusters are listed in Table 3. The smallest cluster is built of a pair of $\mathrm{V}-\mathrm{O}$ square pyramids, the next in order accounts for $\mathrm{P}-\mathrm{O}$ tetrahedra that separate the $\mathrm{V}_{2} \mathrm{O}_{10}$ unit one from the other, whereas in the $\mathrm{V}_{10} \mathrm{P}_{6} \mathrm{O}_{50} \mathrm{H}_{30}$ cluster half of the building unit of the $(\mathrm{VO})_{2} \mathrm{P}_{2} \mathrm{O}_{7}$ has its appropriate surface environment. Here, like in the case of ZINDO treatment, we have restricted the analysis to the $\mathrm{V}_{2} \mathrm{P}_{2} \mathrm{O}_{6}$ fragment shown at Fig. 4. Discussing the results we see the variation in atom charging when going from the V2 to V10 clusters however, the difference is not a dramatic one and concerns only the cluster without $\mathrm{PO}_{4}$ groups. The biggest differences are for doubly $\mathrm{O} 2$ and triply $\mathrm{O} 3$ coordinated oxygen sites ( 0.18 and $0.21 \mathrm{e}$, respectively) and result from a fact that in this cluster neither $\mathrm{O} 2$ nor $\mathrm{O} 3$ oxygen atoms have their proper surface neighbors. For both the phosphorous atom is replaced by the hydrogen atom that saturates the cluster. Increasing the size of the cluster, by going from $\mathrm{V}_{2} \mathrm{P}_{6} \mathrm{O}_{26} \mathrm{H}_{14}$ to $\mathrm{V}_{10} \mathrm{P}_{6} \mathrm{O}_{50} \mathrm{H}_{30}$ cluster accounts for the appropriate neighbors in half of the building unit of the $(\mathrm{VO})_{2} \mathrm{P}_{2} \mathrm{O}_{7}$ (the second half differs by a small variation in bonding distances, see Fig. 1).

Let us now discuss the $\mathrm{V}_{10} \mathrm{P}_{6} \mathrm{O}_{50} \mathrm{H}_{30}$ cluster which according to ZINDO calculations can represent the extended $(\mathrm{VO})_{2} \mathrm{P}_{2} \mathrm{O}_{7}\left(\begin{array}{lll}1 & 0 & 0\end{array}\right)$ surface. In agreement with chemical reasoning all vanadium and phosphorous atoms are positively charged whereas all oxygen posses negative charges. According to DFT results the vanadium atoms V1 and V2 are described by atomic charges +0.93 and +1.06 and phosphorous atoms $\mathrm{P} 1$ and $\mathrm{P} 2$ by +1.33 and +1.30 . The oxygen atoms are differently charged depending on their coordination number. The most negatively charged $(-0.74)$ is the triply coordinated oxygen, O3, that have two vanadium and one phosphorous atoms as the neighbors. Next in order is a doubly coordinated oxygen $\mathrm{O} 2(-0.60)$ that binds to one vanadium and 
Table 3

Mulliken population and Mayer bond indices for the selected atoms (see Fig. 4) of $\mathrm{V}_{2} \mathrm{O}_{8} \mathrm{H}_{8}, \mathrm{~V}_{2} \mathrm{P}_{6} \mathrm{O}_{26} \mathrm{H}_{14}, \mathrm{~V}_{10} \mathrm{P}_{6} \mathrm{O}_{50} \mathrm{H}_{30}$ clusters obtained by DFT method

\begin{tabular}{|c|c|c|c|}
\hline Atoms & $\mathrm{V}_{2} \mathrm{O}_{8} \mathrm{H}_{8}$ & $\mathrm{~V}_{2} \mathrm{P}_{6} \mathrm{O}_{26} \mathrm{H}_{14}$ & $\mathrm{~V}_{10} \mathrm{P}_{6} \mathrm{O}_{50} \mathrm{H}_{30}$ \\
\hline \multicolumn{4}{|l|}{ Charges } \\
\hline $\mathrm{V} 1=\mathrm{O} 1$ & $0.85 /-0.30$ & $0.99 /-0.23$ & $0.94 /-0.22$ \\
\hline $\mathrm{V} 2=\mathrm{O} 1^{\prime}$ & $0.93 /-0.36$ & $1.11 /-0.30$ & $1.06 /-0.29$ \\
\hline $\mathrm{P} 1=\mathrm{O} 1$ & - & $1.18 /-0.64$ & $1.33 /-0.57$ \\
\hline $\mathrm{P} 2=\mathrm{O} 1^{\prime}$ & - & $1.19 /-0.60$ & $1.30 /-0.59$ \\
\hline $\mathrm{V} 1-\mathrm{O} 2-\mathrm{P} 1$ & -0.78 & -0.58 & -0.60 \\
\hline $\mathrm{V} 1-\mathrm{O} 3-\mathrm{V} 2-\mathrm{P} 2$ & -0.95 & -0.71 & -0.74 \\
\hline \multicolumn{4}{|c|}{ Distances $(R)$ and bond orders } \\
\hline$R(\mathrm{~V} 1=\mathrm{O} 1)=1.55$ & 2.29 & 2.36 & 2.36 \\
\hline$R\left(\mathrm{~V} 2=\mathrm{O}^{\prime}\right)=1.73$ & 2.20 & 2.27 & 2.26 \\
\hline$R(\mathrm{P} 1=\mathrm{O} 1)=1.63$ & - & 1.66 & 1.59 \\
\hline$R\left(\mathrm{P} 2=\mathrm{O}^{\prime}\right)=1.56$ & - & 1.81 & 1.78 \\
\hline$R(\mathrm{~V} 1-\mathrm{O} 2)=2.00$ & 0.93 & 0.49 & 0.63 \\
\hline$R(\mathrm{P} 1-\mathrm{O} 2)=1.53$ & 0.74 & 1.36 & 1.23 \\
\hline$R(\mathrm{~V} 1-\mathrm{O} 3)=2.09$ & 0.16 & 0.38 & 0.42 \\
\hline$R(\mathrm{~V} 2-\mathrm{O} 3)=2.05$ & 0.15 & 0.36 & 0.42 \\
\hline$R(\mathrm{P} 2-\mathrm{O} 3)=1.56$ & $0.63^{\mathrm{a}}$ & 1.01 & 0.90 \\
\hline
\end{tabular}

${ }^{a}$ Here $\mathrm{P}=2 \mathrm{H}$ which saturate cluster.

one phosphorous. Very similar in the nucleophilic character to $\mathrm{O} 2$ are the oxygens singly coordinated to phosphorous, $\mathrm{O} 1$ and $\mathrm{O}^{\prime},(-0.57,-0.59$, respectively) whereas the vanadyl oxygen atoms, $\mathrm{O} 1$ and $\mathrm{O}^{\prime}$, bonded to vanadium are characterized by the weakest nucleophilic character $(-0.22,-0.29$, respectively).

Atom charges in the clusters can yield information about local ionicities and ionic (electrostatic) binding between the $\mathrm{V}$ and $\mathrm{O}$ or $\mathrm{P}$ and $\mathrm{O}$ atoms. In contrast, bond order results give a rough estimate of covalent contributions to the total $\mathrm{V}-\mathrm{O}$ and $\mathrm{P}-\mathrm{O}$ bonds. The results of Table 3 confirm the general picture based on simple valence concepts. The bond order describing bonds between terminal oxygens $\left(\mathrm{O} 1, \mathrm{O}^{\prime}\right)$ and vanadium atoms yield values above 2 that suggests both vanadyl bonds being the strong double bonds. A noticeable difference in distances in two vanadyl groups (1.55 and $1.73 \AA$ ) manifests only slightly both in charging and bond orders (2.36 against 2.26). The oxygen atoms singly coordinated to $\mathrm{P}$ atoms $\left(\mathrm{O} 1, \mathrm{O}^{\prime}\right)$ form bonds of the character between the double and the single ones. In this case however, a small difference in $\mathrm{P}-\mathrm{O}$ bond distances (1.63 and $1.56 \AA$ ) results in a quite big difference in bond orders (1.59 against 1.78). The doubly coordinated (O2) oxygen forms two bonds with its partners, quite a weak one (0.63) with $\mathrm{V}$ and more than a single one (1.23) with $\mathrm{P}$ atom. The similar situation is in the case of the triply coordinated oxygen (O3), almost the single bond (0.90) with phosphorous atom and two very weak bonds (0.42) with vanadium atoms.

The surface of vanadyl pyrophosphate is the platform for various reactions including bond formation with an adsorbate, reconstruction of the surface and penetration of the adsorbate into the surface. To adsorb organic molecule two mechanisms are possible: a transfer of HOMO electrons from the cluster to LUMO of the molecule (leading to an activation of an organic molecule via for example bond breaking) or the transfer of electrons from the organic species into the LUMO of the cluster. To describe the chemical behavior of the surface, Fig. 6 shows the population distribution and the respective electron wavefunction for HOMO whereas Fig. 7 the population distribution and wavefunction for LUMO for $\mathrm{V}_{10} \mathrm{P}_{6} \mathrm{O}_{50} \mathrm{H}_{30}$ cluster. Both the population distribution and the character of the electron wavefunction indicate that the 
(a)

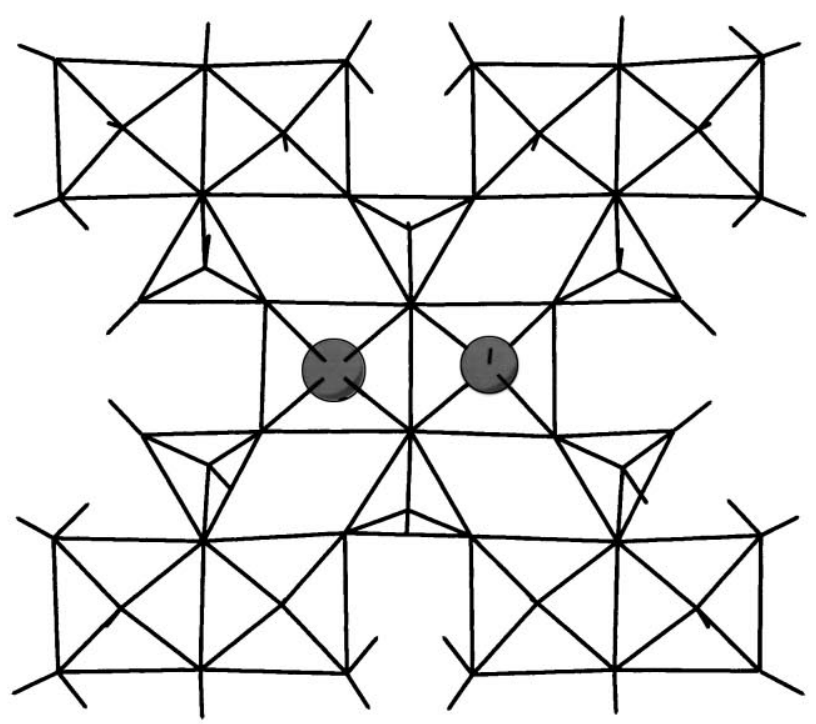

(b)

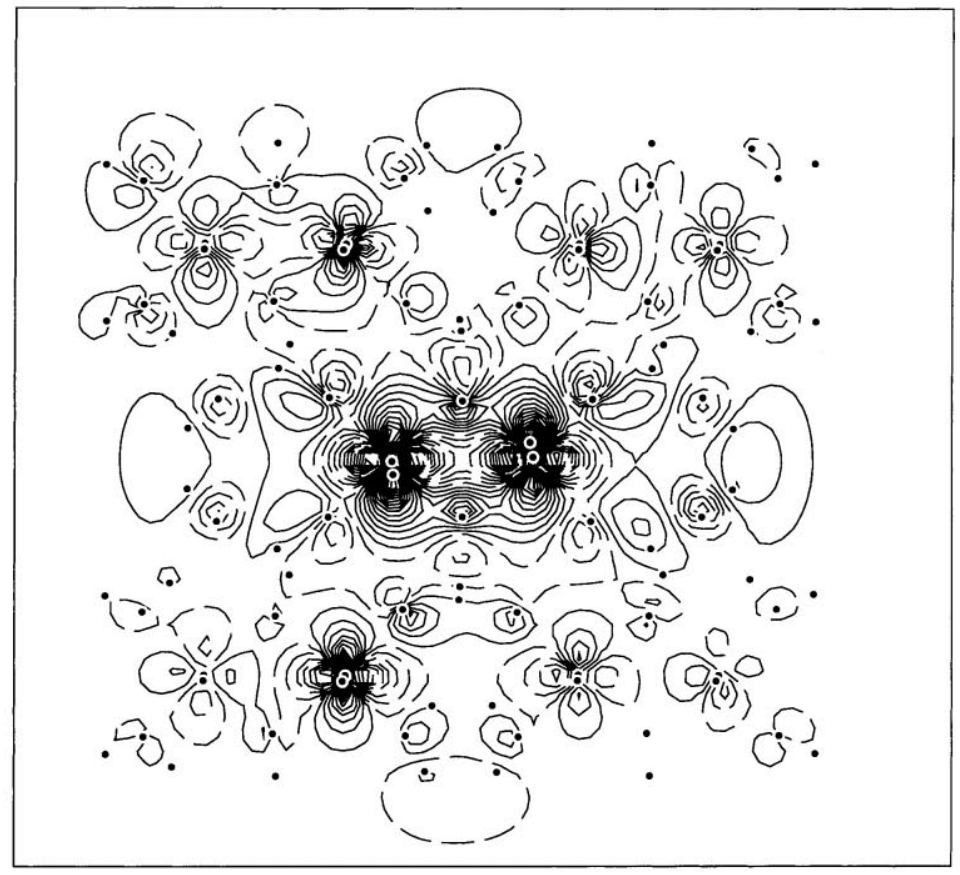

Fig. 6. Population distribution for the orbitals of HOMO and electron wavefunctions describing the highest occupied molecular orbital in case of $\mathrm{V}_{10} \mathrm{P}_{6} \mathrm{O}_{50} \mathrm{H}_{30}$ cluster. The respective Mulliken populations determine atomic radii, cut has been done through $(100)$ plane. 
(a)

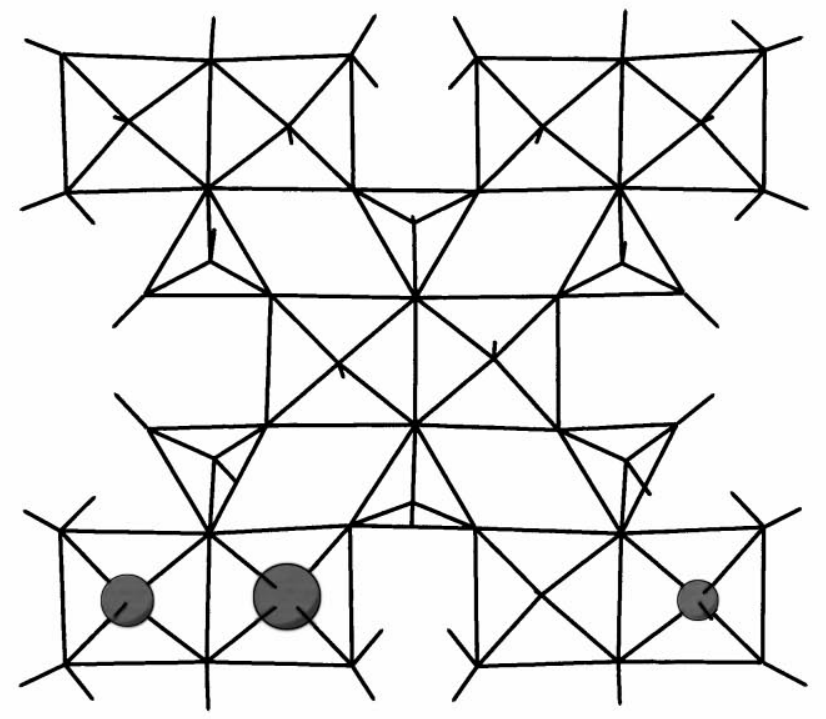

(b)

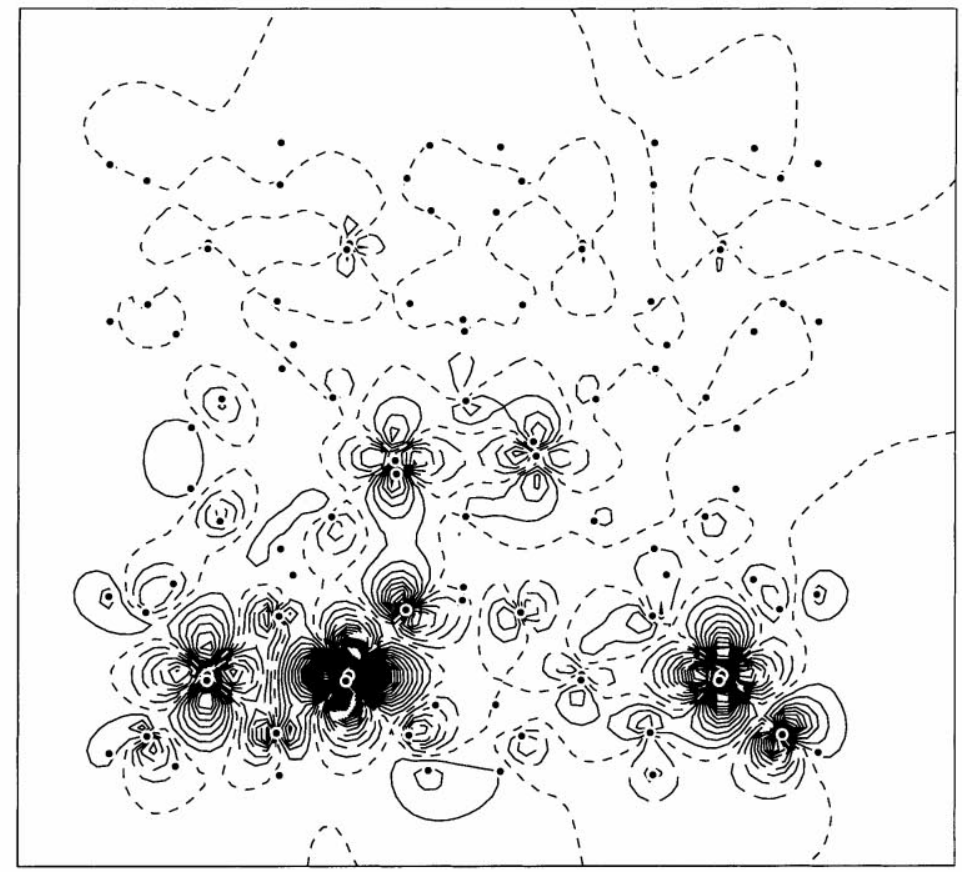

Fig. 7. Population distribution for the orbitals of LUMO and electron wavefunctions describing the highest unoccupied molecular orbital in case of $\mathrm{V}_{10} \mathrm{P}_{6} \mathrm{O}_{50} \mathrm{H}_{30}$ cluster. The respective Mulliken populations determine atomic radii, cut has been done through (100) plane. 
main contribution to HOMO and LUMO comes from vanadium $3 \mathrm{~d}$ types function. Thus, it can be seen that both mechanisms can operate. Which of them really takes place would depend on the mutual position of the energy levels of HOMO/LUMO of the clusters and of the $\mathrm{C}-\mathrm{H}$ bond of the incoming molecule. A mechanism of the $\mathrm{C}-\mathrm{H}$ activation requires the more detailed studies and is a subject of our current calculations.

\section{Summary}

The electronic structure of the surface is responsible for the interaction and binding with the reactant(s), for resulting bond changes, for the reaction between the adsorbed reactant(s) and for the desorption process. Therefore, the knowledge of the electronic properties of the surface is of the greatest importance. The present cluster studies which combine semiempirical and ab initio DFT approaches provide detailed information on the electronic structure of the $(\mathrm{VO})_{2} \mathrm{P}_{2} \mathrm{O}_{7}\left(\begin{array}{lll}1 & 0 & 0\end{array}\right)$ surface. This applies in particular to the behavior of differently coordinated surface oxygen sites that can participate in catalytically activated reactions at the surface of vanadyl pyrophosphate. The calculations are the first ones performed on the ab initio level.

The electronic parameters calculated for the present cluster models are size converged and the cluster as large as $\mathrm{V}_{10} \mathrm{P}_{6} \mathrm{O}_{50} \mathrm{H}_{30}$ can be considered the realistic model of the extended $(\mathrm{VO})_{2} \mathrm{P}_{2} \mathrm{O}_{7}\left(\begin{array}{lll}1 & 0 & 0\end{array}\right)$ surface. The theoretical data based ab initio DFT method confirm the ionic character of the material where, however, major covalent contributions participate both in the $\mathrm{V}-\mathrm{O}$ and $\mathrm{P}-\mathrm{O}$ binding. The calculations reveal clear electronic differences between structurally different surface oxygen atoms. Triply coordinated oxygen sites (O3) are found to be the most negatively charged. The relatively small difference in charges between doubly coordinated oxygen sites (O2) and oxygen atoms singly coordinated to phosphorous may indicate similar local reactivity of these sites with respect to electrophilic attacks. The strong nucleophilicity of surface oxygen sites together with the V3d character of HOMO/LUMO suggest that the interaction of adsorbate with the $(\mathrm{VO})_{2} \mathrm{P}_{2} \mathrm{O}_{7}(100)$ surface will lead to the activation of organic species proceeding via to $\mathrm{C}-\mathrm{H}$ bond splitting.

\section{Acknowledgements}

This work has been supported by grant No. 3T09A 14615 of the State Committee for Scientific Research in Poland.

\section{References}

[1] B. Grzybowska-Swierkosz, F. Trifiro, J.C. Vedrine, (Eds.), Vanadia Catalysts for Selective Oxidation of Hydrocarbons and Their Derivatives, J. Appl. Catal. 157 (1997) 1-425 (special issue).

[2] B.Grzybowska-Swierkosz, J. Haber, (Eds.), Vanadia Catalysts for Processes of Oxidation of Aromatic Hydrocarbons, PWN-Polish Scientific Publishers, Warsaw, 1984.

[3] E. Bordes, Catal. Today 1 (1987) 499.

[4] E. Bordes, Catal. Today 3 (1988) 163.

[5] M.R. Thompson, J.R. Ebner, New developments in selective oxidation iby heterogeneous catalysis, in: P. Ruiz, B. Delmon (Eds.), Studies in Surface Science and Catalysis, Vol. 72, 1992, p. 353.

[6] J.W. Johnson, D.C. Johnston, A.J. Jacobson, J.F. Brody, J. Am. Chem. Soc. 106 (1984) 8123.

[7] E. Bordes, P. Courtine, J. Solid State Chem. 55 (1984) 270

[8] P.T. Nguyen, A.W. Sleight, Book of Abstracts, American Chemical Society Meeting 1996, p. 201.

[9] N. Duvauchelle, E. Kesteman, F. Oudet, E. Bordes, J. Solid State Chem. 137 (1998) 311.

[10] N. Duvauchelle, E. Bordes, Catal. Lett. 57 (1999) 81.

[11] P. Amoros, M.D. Mareos, A. Beltran-Poster, D. Beltran-Poster, Curr. Opinion Solid State Mater. Sci. 4 (1999) 123.

[12] G.J. Hutchings, Appl. Catal. 72 (1991) 1.

[13] G. Centi, F. Trifiro, J.R. Ebner, V.M. Franchetti, Chem. Rev. 88 (1988) 55.

[14] G. Busca, G. Centi, J. Am. Chem. Soc. 111 (1989) 46.

[15] G. Centi, Catal. Today 16 (1993) 5.

[16] F. Cavani, F. Trifiro, Catalysis 11 (1994) 247.

[17] J.R. Ebner, M.R. Thompson, Catal. Today 16 (1993) 51.

[18] Y. Zhang-Lin, M. Forissier, R.P. Sneeden, J.C. Vedrine, J.C. Volta, J. Catal. 145 (1994) 256.

[19] Y. Zhang-Lin, M. Forissier, J.C. Vedrine, J.C. Volta, J. Catal. 145 (1994) 267.

[20] N. Song, D. Zhang, H. Huang, H. Zhao, F. Tian, Catal. Today 51 (1999) 85.

[21] U. Rodemerck, B. Kubias, H.-W. Zanthoff, M. Baerns, Appl. Catal. A: General 153 (1997) 203.

[22] U. Rodemerck, B. Kubias, H.-W. Zanthoff, G.-U. Wolf, M. Baerns, Appl. Catal. A: General 153 (1997) 217.

[23] V.A. Zazhigalov, J. Haber, J. Stoch, L.V. Bogutskaya, I.V. Bacherikova, Appl. Catal. A: General 135 (1996) 155.

[24] P.A. Agaskar, L. DeCaul, R.K. Grasselli, Catal. Lett. 23 (1994) 339.

[25] J. Ziolkowski, E. Bordes, P. Courtine, J. Mol. Catal. 84 (1993) 307. 
[26] J. Ziolkowski, E. Bordes, P. Courtine, J. Catal. 122 (1990) 126.

[27] B. Schiott, K.A. Jorgensen, R. Hoffmann, J. Phys. Chem. 95 (1991) 2297.

[28] J. Haber, R. Tokarz, M. Witko, in: B.K. Warren, S.T. Oyama (Eds.), Heterogeneous Hydrocarbon Oxidation, ACS Symp. Ser. 638 (1996) 249.

[29] V. Robert, S.A. Borshch, B. Bigot, J. Mol. Catal. 119 (1997) 327.

[30] M.R. Thompson, A.C. Hess, J.B. Nocholas, J.C. White, J. Anchell, J.R. Ebner, New developments in selective oxidation II, in: V. Cortes-Corberan, S. Vic Bellon (Eds.), Studies in Surface Science and Catalysis, Vol. 82, 1994, p. 167.

[31] Y.E. Gubanova, S.A. Linde, Doklady Akademii Nauk SSSR 245 (1979) 584-588.

[32] J. Tomasi, J. Mol. Struct. Theochem 179 (1988) 273.

[33] M.C. Zerner, G.H. Loew, R.F. Kirchner, U.T. Muller-Westerhoff, J. Am. Chem. Soc. 102 (1980) 589.

[34] A.D. Bacon, M.C. Zerner, Theor. Chim. Acta 53 (1979) 21.
[35] W.D. Edwards, M.C. Zerner, Theor. Chim. Acta 72 (1987) 347.

[36] A. Szabo, N.S. Ostlund, Modern Quantum Chemistry: Introduction to Advanced Electronic Structure Theory, Macmillan, New York, p. 1092.

[37] E. Wimmer, in: J.K. Labanowski, J.W. Andzelm (Eds.), Density Functional Methods in Chemistry, Springer, Heidelberg, 1991.

[38] N. Godbout, D.R. Salahub, J. Andzelm, E. Wimmer, Can. J. Phys. 70 (1992) 560.

[39] The DFT-LCGTO program package DeMon developed by A. St. -Amant and D. Salahub with modifications and extensions by L.G.M. Pettersson and K. Hermann.

[40] S.H. Vosko, L. Wilk, M. Nusair, Can. J. Phys. 58 (1980) 1200.

[41] R.S. Mulliken, J. Chem. Phys. 23 (1955) 1833, 1841, 2388, 2343.

[42] I. Mayer, Chem. Phys. Lett. 97 (1983) 270.

[43] I. Mayer, J. Mol. Struct. Theochem 149 (1987) 81.

[44] M. Witko, R. Tokarz, J. Haber, J. Mol. Catal. 66 (1991) 357. 